\title{
Diagnostic Performance of Polymerase Chain Reaction Targeting Insertion Sequence (IS6110) for the Detection of Extra Pulmonary Tuberculosis
}

\author{
A. Chitra ${ }^{1}$, B. Usharani ${ }^{2}$, S. Smita ${ }^{1}$, C. K. Vidya Raj ${ }^{1}$, S. Anbazhagi ${ }^{3}$, M. Muthuraj ${ }^{1, *}$ \\ ${ }^{1}$ State TB Training and Demonstration Centre, Intermediate Reference Laboratory, Government Hospital for Chest Diseases, \\ Puducherry, India \\ ${ }^{2}$ Department of Biomedical Genetics, Institute of Basic Medical Sciences, University of Madras, Tamil Nadu, India \\ ${ }^{3}$ Department of Environment Science, Central University, Kerala, India \\ *Corresponding author: muthuraj1970@gmail.com
}

\begin{abstract}
Background: The diagnostic challenges in extra-pulmonary tuberculosis remain to be addressed even though remarkable progress has been made in the diagnostics of pulmonary tuberculosis during the last decade. Methods: This study was conducted to evaluate the use of polymerase chain reaction (PCR) in diagnosis of definitive extra pulmonary tuberculosis patients, and to assess the performance of insertion sequence (IS)6110 based PCR assay as compared to conventional liquid culture by Microbial growth Indicator Tube (MGIT) 960 system. Results: A total of 792 clinical specimens were collected from clinically suspected extra pulmonary tuberculosis patients. The specimens included 22 ascitic fluids, 69 pleural fluids, 240 Cerebrospinal fluids (CSF), 386 endometrial tissues, 47 lymph nodes, 22 pus, one synovial fluid, one fallopian tube, two brain abscess and two ovarian cyst samples. All these clinical samples were subjected to Auromine O staining (FM) for acid fast bacilli (AFB) and culture on MGIT 960 tubes containing Modified Middlebrooks 7H9 broth medium. PCR was performed by targeting 123bp fragment of insertion sequence IS6110 of Mycobacterium tuberculosis. Our study of 792 specimens, revealed their $87.5 \%$ sensitivity to endometrial samples, $92.31 \%$ sensitivity for cerebrospinal fluid, and 66.66\% sensitivity in Pleural fluid and 60\% sensitivity in Lymph node samples. The combined sensitivity and specificity of the PCR IS6110 was calculated to be $85.71 \%$ and $82.91 \%$, respectively. Conclusion: PCR using IS6110 primer was able to pick up more positivity in extra pulmonary samples as compared to conventional culture method for the detection of $M$. tuberculosis.
\end{abstract}

Keywords: polymerase chain reaction, mycobacterium tuberculosis, extra pulmonary tuberculosis, insertion sequence, cerebrospinal fluid

Cite This Article: A. Chitra, B. Usharani, S. Smita, C. K. Vidya Raj, S. Anbazhagi, and M. Muthuraj, "Diagnostic Performance of Polymerase Chain Reaction Targeting Insertion Sequence (IS6110) for the Detection of Extra Pulmonary Tuberculosis." American Journal of Infectious Diseases and Microbiology, vol. 5, no. 4 (2017): 126-131. doi: 10.12691/ajidm-5-4-1.

\section{Introduction}

Tuberculosis has been a foremost global public health problem from times immemorial. World Health Organization (WHO) estimates show that globally there are 9.4 million incident cases of TB of which $80 \%$ are in 22 countries, with India ranked as the highest burdened country, accounting for one-fifth of the global TB incidence. TB remains the largest infectious killer disease affecting adults in developing countries [1]. TB manifests clinically as pulmonary or extra pulmonary tuberculosis (EPTB), with the former being more common. In India, 10 to $15 \%$ of TB cases are estimated to be cases of extra pulmonary tuberculosis (which affects mainly the lymph nodes, meninges, kidney, spine, and growing ends of the bones), with a 25 to $50 \%$ case mortality rate within months [2].
The global burden of extra pulmonary tuberculosis constitutes about 15 to $20 \%$ of all cases of TB. The annual global incidence of extra pulmonary tuberculosis has been increasing in the last decade due to the changing TB control practices, spread of HIV (human immunodeficiency virus), the population growth and the cure of infectious cases of TB might have resulted in a relative rise of annual extra pulmonary tuberculosis case detection. HIV pandemic further complicates the situation, as extra pulmonary tuberculosis constitutes more than $50 \%$ of all cases of TB in HIV-positive patients. HIV co-infected TB patients often develop extra pulmonary involvement that may progress rapidly unless the infection is diagnosed and they are treated appropriately [3].

The diagnosis of extra pulmonary tuberculosis poses a particular challenge for clinician because of the protean ways in which the disease presents. Diagnosis of this condition requires high clinical suspicion and special 
diagnostic procedures. The diagnosis of extra pulmonary tuberculosis may not be difficult in a few cases with concomitant pulmonary involvement. However, patients with the extra pulmonary tuberculosis are more likely to have negative sputum smear results and many extra pulmonary tuberculosis cases do not have direct lung involvement. The extra pulmonary tuberculosis diagnosis is lacking more in rural health facilities which are being used by about $70 \%$ of the population in developing countries. Here, the diagnosis largely depends on unreliable methods such as ZN microscopy, histology, and tuberculin test [4]. Direct AFB (acid fast bacilli) smear and L-J (Lowenstein-Jensen) culture lack sensitivity for diagnosis of extra pulmonary tuberculosis and culture takes at least two weeks. Smear for AFB is reported to be positive in 10 to 37 percent of patients and L-J culture is reported positive in variable proportion (12 to 80\%) in different body fluids from suspected extra pulmonary tuberculosis cases [5].The existing methodologies remain ineffective due to less number of mycobacteria and/or because of time consuming procedures. Accurate and early diagnosis of $\mathrm{TB}$ is crucial for its effective management and timely treatment. At present, nucleic acid amplification based assays are the most suitable choices for the identification of Mycobacterium tuberculosis in smear negative samples with high degree of sensitivity and specificity [6,7]. Several studies have been performed to detect $M$. tuberculosis in pulmonary and extra pulmonary clinical samples using PCR targeting different DNA sequences of $M$. tuberculosis [8]. The purpose of this study was to evaluate the effectiveness of PCR in diagnosis of definitive and probable extra pulmonary tuberculosis patients, and to assess the performance of insertion sequence (IS) 6110 based PCR assay as compared to conventional culture by MGIT method for the diagnosis of extra pulmonary tuberculosis.

\section{Materials and Methods}

All samples were received from eight Medical Colleges in Puducherry state, Government Hospitals and Primary Health centres and were assigned Laboratory number to process the samples at Intermediate Reference Laboratory of Government Hospital for Chest Diseases. The study was done prospectively in a blinded manner in which the clinical diagnosis was not available to the Laboratory personnel. Seven hundred ninety two samples from 792 patients were included in the study and included pleural fluids (n-53), endometrial tissues (n-383), Cerebrospinal fluids (n-237), Pus (n-25), lymph node biopsies (n-73), Ascetic fluids (n-29), ovarian cyst (n-2), Fallopian tubes (n-2), Synovial fluid (n-1), and Brain abscesses (n-1) (Table 1). The inclusion criteria adopted in the selection of patients were untreated patients with features of fever, cough, pleuritic pain, malaise, anorexia, and extensive exudative pleural effusion on diagnostic pleural tap, a with clinical working diagnosis of tuberculous pleural effusion. Patients with histories of tuberculosis in the preceding 2 years, those already receiving antituberculosis therapy, and those with other coexisting medical and surgical illness were excluded from the study.

\section{Processing of Extra Pulmonary Samples for MGIT 960 System}

\subsection{Pus and Other Muco-purulent Specimens}

Pus and mucopurulent specimens were decontaminated by N-Acetyl L-Cysteine (NALC) or sodium hydroxide $(\mathrm{NaOH})$ procedure for $15-20 \mathrm{~min}$ and centrifuged at 4000 rpm for $15 \mathrm{~min}$. After the falcon tubes were removed from the centrifuge, the supernatant was carefully poured off into a suitable container containing a mycobactericidal disinfectant.. The falcon tubes were filled with $20 \mathrm{ml}$ of sterile phosphate buffer ( $\mathrm{pH}$ 6.8), shaken by hand to mix the deposit and were centrifuged for 15 minutes at 4000 rpm. The supernatant was poured off and using a sterile transfer pipette added $0.5 \mathrm{ml}$ of the processed sediment to a MGIT 960 tube containing Modified Middlebrooks 7H9 broth previously inoculated with $0.8 \mathrm{ml}$ of the PANTA-growth supplement mixture. Tubes were loaded into instrument on the same day as processing/inoculation [9].

\subsection{Tissue}

The endometrial tissue was homogenized in a presterilised tissue grinder with a small quantity of sterile saline (2-4 $\mathrm{ml})$ and the homogenized specimen was decontaminated using NALC-NaOH procedure. Following centrifugation, the pellet in each tube was suspended in $2.5 \mathrm{ml}$ of phosphate buffer $\mathrm{pH}$ 6.8. After resuspension of the sediment with phosphate buffer, inoculated $0.5 \mathrm{ml}$ into MGIT 960 tube. Any processed specimen remaining after initial cultures was stored at $-20^{\circ} \mathrm{C}$ for the duration of the study to allow for re-testing of specimens in case of invalid results [9].

\subsection{Other Body Fluids (Cerebrospinal Fluid, Ascitic fluid, Pericardial Fluid, Synovial Fluid and Pleural Fluid)}

Sterile body fluid samples (ascitic fluid, pleural fluid, Cerebrospinal fluid, synovial fluid, pericardial fluid and pancreatic cyst fluid) were decontaminated by NALC/NaOH procedure for $20 \mathrm{~min}$ and centrifuged at $4000 \mathrm{rpm}$ for 15 min. After the falcon tubes were removed from the centrifuge, the supernatant was carefully poured off into the disinfectant bath. The falcon tubes were filled with 20 $\mathrm{ml}$ of sterile distilled water, shaken by hand to mix the deposit and were centrifuged for 15 minutes at $4000 \mathrm{rpm}$. The supernatant was poured off and using a sterile transfer pipette added $0.5 \mathrm{ml}$ of the processed sediment to a MGIT 960 tube previously inoculated with $0.8 \mathrm{ml}$ of the PANTA-growth supplement mixture. Tubes were loaded into instrument on the same day as processing/inoculation [10].

\subsection{Extraction Target DNA from Clinical Samples}

DNA was extracted according to the CTAB-phenol chloroform extraction method. Briefly, the pellet was 
suspended in $100 \mu \mathrm{l}$ of TE buffer (Tris EDTA, pH7.4).The entire pellets were treated with $50 \mu \mathrm{l}$ of lysozyme $(10 \mathrm{mg} / \mathrm{ml})$ at $37^{\circ} \mathrm{C}$ for overnight incubation. Added $70 \mu \mathrm{l}$ of $14 \%$ SDS and $6 \mu$ l Proteinase K $(10 \mathrm{mg} / \mathrm{ml})$, mixed and incubated at $65^{\circ} \mathrm{C}$ for 15 minutes. After incubation, $10 \mu \mathrm{l}$ of $5 \mathrm{M} \mathrm{NaCl}$ and $80 \mu \mathrm{l}$ of high salt CTAB buffer (containing $5 \mathrm{M} \mathrm{NaCl}, 1.8 \% \mathrm{CTAB}$ ) was added and mixed followed by incubation at $65^{\circ} \mathrm{C}$ for 10 minutes. An approximate equal volume $(0.7-0.8 \mathrm{ml})$ of Phenol: Chloroform: Iso amyl alcohol(25:24:1) was added, mixed thoroughly and centrifuged at $4^{\circ} \mathrm{C}$ for 10 minutes in a micro centrifuge at 12000rpm.The supernatant was separated and then mixed with $0.6 \mathrm{ml}$ volume of ice cold isopropanol to get precipitates. The precipitated nucleic acids were washed with $70 \%$ ethanol, dried and resuspended in $25 \mu$ l of $1 \mathrm{X}$ TE buffer [11].

\subsection{PCR Amplification}

The extracted DNA template was used for the amplification using IS6110 insertion sequence primer specific to Mycobacterium tuberculosis complex. The sequences of the two primers used were: Forward primer F 5'GTGAGGGCATCGAGGTGG 3': R 5'CGTAGGC GTCGGTCACAAA 3' [12]. The amplification was performed on the total reaction volume of $50 \mu \mathrm{l}$ with $2 \mu \mathrm{l}$ of extracted DNA,25 $\mu$ l of Master mix (Eppendorf 2X), $2 \mu \mathrm{l}$ of each primer $(10 \mathrm{pmol} / \mu \mathrm{l})$ using Master cycler gradient (eppendorf, USA).Initial denaturation at $95^{\circ} \mathrm{C}$ for 5 minutes was proceeded by 35 cycles each of denaturation $\left(95^{\circ} \mathrm{C}\right.$ for $\left.1 \mathrm{~min}\right)$, annealing $\left(57^{\circ} \mathrm{C}\right.$ for $\left.1 \mathrm{~min}\right)$ and extension $\left(72^{\circ} \mathrm{C}\right.$ for $\left.1 \mathrm{~min}\right)$ followed by a final extension at $72^{\circ} \mathrm{C}$ for 10 minutes. The amplified product was electrophoresed into 1\%agarose gel. The gels were stained with ethidium bromide and visualized in a UV-transilluminator (Spectroline, France).

\section{Results}

Among the seven hundred and ninety two extra pulmonary specimens received (Table 1), 169 (21.34\%) were definitive extra pulmonary tuberculosis. Out of the 169 confirmed tuberculosis, 58 were Cerebrospinal fluid, 52 were endometrial tissue, 20 were Pleural fluid, 20 were Lymph node and 9 were ascitic fluid (Table 3) 159(66.25) Cerebrospinal fluid samples were received from paediatric and positivity was 40(25.16\%). 51(15.32\%) definite positive tuberculosis were among the 333 (86.27\%) samples received from age group between 15 to 45 years (Table 2). Among 47 Lymph node cases, 20(42.55\%) were definitive extra pulmonary tuberculosis. Among the 331 body fluid samples, the definite extra pulmonary tuberculosis were 9 (40.91\%), 20 (28.99\%) and 58 (24.17\%) in ascitic fluid, pleural fluids and Cerebrospinal fluid samples respectively (Table 3 ).

Table 1. Diagnostic categories of specimens

\begin{tabular}{|c|c|c|c|c|c|}
\hline \multirow{2}{*}{$\begin{array}{l}\text { Specimens } \\
\text { Extra pulmonary of specimens } \\
\text { tuberculosis }\end{array}$} & \multirow{2}{*}{$\begin{array}{c}\text { Total no } \\
\mathrm{n}(\mathrm{t})\end{array}$} & \multicolumn{4}{|c|}{ Age groups (years) } \\
\hline & & $<15$ yrs. & $>15$ to $<45$ yrs. & $>45$ to $<60$ yrs. & $>60$ yrs. \\
\hline Cerebrospinal fluid & 240 & 159 & 60 & 15 & 6 \\
\hline Pleural fluid & 69 & 42 & 16 & 6 & 5 \\
\hline Ascetic fluid & 22 & 9 & 8 & 5 & - \\
\hline Endometrial tissues & 386 & - & 384 & 2 & - \\
\hline Pus & 22 & 3 & 16 & 1 & 2 \\
\hline Brain abscesses & 2 & 1 & 1 & - & - \\
\hline Lymph node & 47 & 20 & 26 & - & 1 \\
\hline Synovial fluid & 1 & - & 1 & - & - \\
\hline Fallopian tube & 1 & - & 1 & - & - \\
\hline \multirow[t]{2}{*}{ Ovarian cyst } & 2 & - & 2 & - & - \\
\hline & 792 & 234 & 515 & 29 & 14 \\
\hline
\end{tabular}

Table 2. Performance of PCR Positivity among age groups

\begin{tabular}{|c|c|c|c|c|c|c|c|c|c|}
\hline \multirow{3}{*}{$\begin{array}{l}\text { Specimens of } \\
\text { Extra pulmonary of specimens } \\
\text { tuberculosis }\end{array}$} & \multirow{3}{*}{$\begin{array}{l}\text { Total no } \\
\text { n (t) }\end{array}$} & \multicolumn{8}{|c|}{ Age groups (years) } \\
\hline & & \multicolumn{2}{|c|}{$<15 y$ yrs. } & \multicolumn{2}{|c|}{$>15$ to $<45$ yrs. } & \multicolumn{2}{|c|}{$>45$ to $<60$ yrs. } & \multicolumn{2}{|c|}{$>60$ yrs. } \\
\hline & & n (p) & $\mathrm{n}(\mathrm{n})$ & $\mathrm{n}(\mathrm{p})$ & $\mathrm{n}(\mathrm{n})$ & $\mathrm{n}(\mathrm{p})$ & $\mathrm{n}(\mathrm{n})$ & $\mathrm{n}(\mathrm{p})$ & $\mathrm{n}(\mathrm{n})$ \\
\hline Pleural fluid & 69 & 18 & 24 & 2 & 14 & 0 & 6 & 0 & 5 \\
\hline Ascitic fluid & 22 & 5 & 4 & 4 & 4 & 0 & 5 & 0 & 0 \\
\hline ndometrial tissues & 386 & 0 & 0 & 51 & 333 & 1 & 1 & 0 & 0 \\
\hline Pus & 22 & 1 & 2 & 3 & 13 & 0 & 1 & 1 & 1 \\
\hline Brain abscesses & 2 & 1 & 0 & 1 & 0 & 0 & 0 & 0 & 0 \\
\hline Lymph node & 47 & 11 & 9 & 9 & 17 & 0 & 0 & 0 & 1 \\
\hline Synovial fluid & 1 & 0 & 0 & 1 & 0 & 0 & 0 & 0 & 0 \\
\hline Fallopian tube & 1 & 0 & 0 & 1 & 0 & 0 & 0 & 0 & 0 \\
\hline \multirow[t]{2}{*}{ Ovarian cyst } & 2 & 0 & 0 & 1 & 1 & 0 & 0 & 0 & 0 \\
\hline & 792 & 76 & 158 & 86 & 429 & 5 & 24 & 2 & 12 \\
\hline
\end{tabular}


Table 3. MGIT culture and PCR IS6110 positivity rate in various specimens of suspected extra pulmonary tuberculosis patients $(\mathrm{N}=792)$

\begin{tabular}{|c|c|c|c|c|c|}
\hline \multirow{2}{*}{$\begin{array}{l}\text { Specimens of } \\
\text { Extra pulmonary of specimens } \\
\text { tuberculosis }\end{array}$} & \multirow[b]{2}{*}{ Total no } & \multicolumn{2}{|c|}{ MGIT Results } & \multicolumn{2}{|c|}{ PCR results } \\
\hline & & Positive (\%) & Negative & Positive (\%) & Negative \\
\hline Cerebrospinal fluid & 240 & $13(5.42)$ & 228 & $58(24.17)$ & 182 \\
\hline Pleural fluid & 69 & $9(13.04)$ & 63 & 20(28.99) & 49 \\
\hline Ascitic fluid & 22 & $4(18.18)$ & 18 & $9(40.91)$ & 13 \\
\hline Endometrial tissues & 386 & $16(4.15)$ & 372 & $52(13.47)$ & 334 \\
\hline Pus & 22 & 2(9.09) & 20 & $5(22.73)$ & 17 \\
\hline Brain abscesses & 2 & 0 & 2 & $2(100.00)$ & 0 \\
\hline Lymph node & 47 & $5(10.64)$ & 44 & $20(42.55)$ & 27 \\
\hline Synovial fluid & 1 & 0 & 1 & $1(100.00)$ & 0 \\
\hline Fallopian tube & 1 & 0 & 1 & $1(100.00)$ & 0 \\
\hline \multirow[t]{2}{*}{ Ovarian cyst } & 2 & 0 & 2 & $1(50.00)$ & 1 \\
\hline & 792 & 49(6.19) & 743 & $169(21.34)$ & 623 \\
\hline
\end{tabular}

Table 4. Comparison of PCR IS6110 results with conventional MGIT Culture results

\begin{tabular}{lcc}
\hline N=792 & MGIT Culture Positive for M.tuberculosis $n$ (49) & MGIT Culture negative for M.tuberculosis $n$ (743) \\
\hline PCR IS6110 positive $n$ (169) & 42 & 127 \\
PCR IS6110 negative $n$ (623) & 7 & 616 \\
Sensitivity (\%) & 85.71 & \\
Specificity (\%) & 82.91 & \\
PPV (\%) & 24.85 & \\
NPV ((\%) & 98.88 & \\
Efficiency (\%) & 6.19 & \\
\hline
\end{tabular}

PPV-positive predictive value; NPV-negative predictive value.

Table 5. Performance of PCR in diagnosis of extra pulmonary tuberculosis

\begin{tabular}{|c|c|c|c|c|c|c|c|c|}
\hline \multirow{3}{*}{$\begin{array}{l}\text { Parameters } \\
\text { PCR (+) }\end{array}$} & \multirow{2}{*}{\multicolumn{2}{|c|}{$\begin{array}{l}\text { Endometrium } n \text { (386) } \\
\text { MGIT (+); MGIT (-) }\end{array}$}} & \multirow{2}{*}{\multicolumn{2}{|c|}{$\begin{array}{c}\text { CSF } n(240) \\
\operatorname{MGIT~(+);~MGIT~(-)~}\end{array}$}} & \multirow{2}{*}{\multicolumn{2}{|c|}{$\begin{array}{c}\text { Pleural fluid } n \text { (69) } \\
\text { MGIT (+); MGIT (-) }\end{array}$}} & \multirow{2}{*}{\multicolumn{2}{|c|}{$\begin{array}{l}\text { Lymph node } n \text { (47) } \\
\text { MGIT (+); MGIT (-) }\end{array}$}} \\
\hline & & & & & & & & \\
\hline & 14 & 38 & 12 & 46 & 6 & 14 & 3 & 17 \\
\hline PCR (-) & 2 & 332 & 1 & 181 & 3 & 46 & 2 & 25 \\
\hline Sensitivity (\%) & \multicolumn{2}{|c|}{87.5} & \multicolumn{2}{|c|}{92.31} & \multicolumn{2}{|c|}{66.66} & \multicolumn{2}{|c|}{60.00} \\
\hline Specificity (\%) & \multicolumn{2}{|c|}{89.73} & \multicolumn{2}{|c|}{79.74} & \multicolumn{2}{|c|}{76.67} & \multicolumn{2}{|c|}{59.52} \\
\hline PPV (\%) & \multicolumn{2}{|c|}{26.92} & \multicolumn{2}{|c|}{20.69} & \multicolumn{2}{|c|}{23.08} & \multicolumn{2}{|c|}{15.00} \\
\hline NPV (\%) & \multicolumn{2}{|c|}{99.40} & \multicolumn{2}{|c|}{99.45} & \multicolumn{2}{|c|}{93.88} & \multicolumn{2}{|c|}{92.59} \\
\hline Efficiency (\%) & \multicolumn{2}{|c|}{4.15} & \multicolumn{2}{|c|}{5.42} & \multicolumn{2}{|c|}{13.04} & \multicolumn{2}{|c|}{10.64} \\
\hline
\end{tabular}

PPV, positive predictive value; NPV, negative predictive value.

IS6110 PCR has shown 85.71 percent sensitivity (with 95\% confidential interval) and 82.91 percent specificity (with 95\% Confidential Interval). Overall positive and negative predictive value of IS6110 PCR was observed as 24.85 per cent (with $95 \% \mathrm{CI}$ ) and 98.88 per cent (with 95\% CI) (Table 4). The IS6110 PCR has shown 92.31\%, 87.5\%, 66.66\% and $60.00 \%$ sensitivity for Cerebrospinal fluid, endometerial tissuse, Pleural fluid and Lymph node samples respectively. The specificity of the PCR IS6110 was calculated for the endometrial tissues, Cerebrospinal fluid, Pleural fluid and Lymph node and was 89.73\%, 79.74\%, 76.67\% and $59.52 \%$ respectively (Table 5).

\section{Discussion}

Extra pulmonary tuberculosis is a significant health dilemma in both developed and developing countries. A high degree of suspicion abetted by intensive investigations is important in the diagnosis of the extra pulmonary tuberculosis. The laboratory diagnosis of extra pulmonary tuberculosis is challenging due to the lack of adequate sample amounts or volumes; the paucibacillary nature of the specimens; the distributing of the sample for various diagnostic tests (histology/cytology, biochemical analysis, microbiology, and PCR), resulting in nonuniform distribution of microorganisms; the presence of inhibitors that undermine the performance of nucleic acid amplification-based techniques; and the lack of an efficient sample processing technique universally applicable on all types of extra pulmonary samples. The poor performance of conventional microbiological techniques in extra pulmonary specimens has encouraged the increased use of PCR tests in the laboratory diagnosis of tuberculosis. The exact diagnostic role of PCR assay for $M$. tuberculosis in high prevalence areas for tuberculosis has been assessed in appropriate 
specimens and control groups, particularly in the case of extra pulmonary tuberculosis. In modern practice, clinicians neither start nor stop treatment for this condition based exclusively on PCR results. Taking this into account, the present blind study was conducted to prospectively evaluate the role of the multipurpose. We show here that PCR would be mainly useful for the diagnosis of tuberculous pleural effusion, lymphadenopathy in patients and diagnosis of tuberculosis in Cerebrospinal fluid and endometrial samples where conventional diagnosis fails and where the provisional diagnosis of tuberculosis is made on the basis of clinical presentation and histology/cytology examination without evidence of AFB.

Several genotypic methods have been tried so far for diagnosis of extra pulmonary tuberculosis [13], which include gene coding for the $38 \mathrm{kDa}, 65 \mathrm{kDa}$ heat shock proteins, 85B antigen, IS6110 insertion sequences and 16SrRNA. There is wide variation in specificity and sensitivity for detection of mycobacterial DNA from extra pulmonary samples using IS6110 as target sequence [14]. IS6110 is a long $1191 \mathrm{bp}$ repetitive insertion sequence that is usually present 6-20 times in the $M$. tuberculosis complex genome than other repetitive sequence [15]. Makeshkumar et al reported the amplification of the same 123bp fragment targeted IS6110 in their study. Among 178 samples, 87.2 percent were PCR positive. Negi et al reported 83 percent PCR positivity and Ogusku et al showed 92.1 percent of their samples to be IS6110 positive when compared with $65 \mathrm{kDa}, 38 \mathrm{kDa}$ and MPB 64 specific primers [16,17].

Makeshkumar et al reported 42.85 percent positivity rate in pus, 36 percent in Cerebrospinal fluid and 50 per cent in urine samples. In comparison, our study revealed 13.47\% percent positivity in endometrium, 24.17 percent in Cerebrospinal fluid, 28.99 percent in Pleural fluid and 42.55 percent in Lymph node samples [16]. An earlier Indian study [18] has also reported 63 per cent positivity by PCR using IS6110 element in specimens of extra pulmonary. Most of the studies which used IS6110 based PCR, had reported 90 per cent sensitivity in Cerebrospinal fluid, pleural fluid, ascetic fluid and other extra pulmonary specimens. In comparison, our study revealed 87.5 percent sensitivity in endometrium, 92.31 percent sensitivity in Cerebrospinal fluid, 66.66 percent sensitivity in Pleural fluid and 60 percent sensitivity in Lymph node samples. Tiwari et al had shown 62 percent total positivity rate among extra pulmonary samples and detection of $M$. tuberculosis DNA in 57 percent of AFB smear negative extra pulmonary samples. Our study has shown a low number of PCR positives among the 331 body fluid samples, i.e. 40.91 per cent in ascitic fluid, 28.99 per cent pleural fluids and 24.17 percent Cerebrospinal fluid samples. IS6110 is specific for M. tuberculosis complex and generally occurs in 1-20 copies per cell, which are dispersed in the $M$. tuberculosis genome and it is an ideal target for amplification, one locus, the direct repeat region, has on high frequency of carriage of IS6110 and has been proposed as a "hot spot" for integration of this element, although most of the copies are located at a single site [19]. These insertion elements are present in multiple copies of the genome of $M$. tuberculosis, with 16 copies of IS6110, 6 copies of IS1081 and 2 copies each of IS1547 [20]. The variable copy number of IS6110 among different strains of the tubercle bacilli has led to its extensive use as a genetic marker to investigate the epidemiology of tuberculosis [21].

The advantages of IS6110 PCR are that they are very rapid, easy to perform and result can be delivered for early treatment and can prevent further transmission of tuberculosis infection and the disadvantage with PCR assay is that it is not able to differentiate live bacilli from dead organisms. Further, IS6110 PCR test is more sensitive even when both smear examination and culture results are considered in conjunction. In conclusion, the present study revealed that IS6110 PCR could detect more positives in extra pulmonary tuberculosis when compared with conventional methods. Proper positive and negative control checks and good laboratory practice can eliminate the chances of false positive results.

\section{References}

[1] Dye, C., Global epidemiology of tuberculosis. Lancet, 938-940. 2006.

[2] S.P. Agarwal, L.S. Chauhan, Tuberculosis control in India. Directorate General of Health Services/Ministry of Health and Family Welfare, New Delhi, India. 2005.

[3] Ellner, J. J, The emergence of extensively drug-resistant tuberculosis: a global health crisis requiring new interventions. Part II. Scientific advances that may provide solutions. Clin Transl Sci, 2. 80-84.2009.

[4] Manju Purohit., Tehmina Mustafa, Laboratory Diagnosis of Extrapulmonary Tuberculosis (EPTB) in Resource-constrained Setting: State of the Art, Challenges and the Need. J Clin Diag Res, 9. 1-6. 2015.

[5] Makeshkumar, V., Radha Madhavan., Sujatha Narayanan, Polymerase chain reaction targeting insertion sequence for the diagnosis of extra pulmonary tuberculosis. Indian J Med Res, 139. (6)-166.2014.

[6] Soni, H., Musser, J.M, Molecular diagnosis of mycobacteria. Clin Chem, 47. 809-14. 2001.

[7] Hale, Y.M., Pfyffer, G.E., Salfinger, M,Laboratory diagnosis of mycobacterial infections: new tools and lessons learned. Clin Infect Dis, 33. 834-46. 2001.

[8] Montenegro, S.H., Gilman, R.H., Sheen, P., Cama, R., Caviedes, L., Hopper, T, Improved detection of M. tuberculosis in Peruvian Children by use of hemi nested IS6110 PCR assay. Clin Infect Dis, 36 16-23. 2006.

[9] Telenti, A., Honore, N., Brenasconi, C., March, J.O., Takiff, H.E., Cole, S.T. Genotyping assessment of isoniazid and rifampicin resistance in Mycobacterium tuberculosis: a blind study at reference laboratory level. J Clin Microbiol, 35.719-723.1997.

[10] Usharani Brammacharry,Muthaiah Muthuraj,Diagnostic value of Polymerase Chain Reaction for the rapid diagnosis of clinically suspected tuberculous meningitis, Int J Pharm Bio Sci, 5. 70-77. 2014.

[11] Muthuraj, M., Jagadeesan, S., Ayalusamy, N. Molecular epidemiological study of pyrazinamide resistance in clinical isolates of Mycobacterium tuberculosis from South India. Int $J$ Mol Sci, 11. 2670-2680. 2011.

[12] Fletcher, H.A., Donoghue, H.D., Taylor, G.M., Adri, G.M., Van der Zanden, A.G.M.,Spigelman, M.Molecular analysis of Mycobacterium tuberculosis DNA from a family of 18th century Hungarians. Microbiology, 149. 143-151.2005.

[13] Tiwari, V., Jain, A., Verma, R.K.Amplification of enzyme amplified mycobacterial DNA detection in the diagnosis of pulmonary and extra pulmonary tuberculosis. Indian $J$ Med Res, 118. 224-248. 2003.

[14] Kaneko, K., Onodera, O., Miyatake, T., Tsuji, S.Rapid diagnosis of tuberculous meningitis by polymerase chain reaction (PCR). Neurology, 40. 1617-1618. 1990.

[15] Eisenach, K.D., Cave, M.D., Bates, J.H., Crawford, J.T. Polymerase chain reaction amplification of a repetitive DNA sequence specific for Mycobacterium tuberculosis. J Infect Dis, 161. 977-981. 1990. 
[16] Negi, S.S., Anand, R., Pasha, S.T., Gupta, S., Blasir, S.F., Khare, S.Diagnostic potential of IS6110, $38 \mathrm{kda}, 65 \mathrm{kda}$ and 85B sequence based polymerase chain reaction in the diagnosis of Mycobacterium tuberculosis in clinical specimens. Indian J Med Microbio, 25. 43-9. 2007.

[17] Ogusuk, M.M., Salem, J. I. Analysis of different primers used in the PCR method: diagnosis of tuberculosis in the state of Amazonas. Brazil J Bras Pnemo, 30. 343-9. 2004.

[18] Narayanan, S., Parandaman, V., Narayanan, P.R., Venkatesan, P., Girish, C., Mahadevan, S. Evaluation of PCR using TRC (4) and IS6110 primers in detection of tuberculous meningitis. J Clin Microbiol, 39. 2006-2008. 2001.
[19] Van Embden, J.D.A., Cave, M.D., Crawford, J.T., Dale, J.W., Eisenach, K.D., Gicquel, B.Strains identification of Mycobacterium tuberculosis by DNA fingerprinting: recommendations for standardized methodology. J Clin Microbiol, 31. 406-409. 1993.

[20] Cole, S.T., Brosch, R., Parkhill, J., Garnier, T., Churcher, C., Harris, D. Deciphering the biology of Mycobacterium tuberculosis from the complete genome sequence. Nature, 393.537-544.1998.

[21] Small, P.M., Hopewell, P.C., Singh, S.P., Paz, A., Parsonnet, J., Ruston, D.C. The epidemiology of tuberculosis in san Francisco. A population-based study using conventional and molecular methods. N Engl J Med, 330.1703-1709.1994. 